\title{
Drivers of drying on the Yongding River in Beijing
}

\author{
Bo Jiang ${ }^{\mathrm{a}}$, Christina P. Wong ${ }^{\mathrm{b}}$, Fei Lu ${ }^{\mathrm{a}}$, Zhiyun Ouyang ${ }^{\mathrm{a}, *}$, Yajuan Wang ${ }^{\mathrm{c}}$ \\ a State Key Laboratory of Urban and Regional Ecology, Research Center for Eco-Environmental Sciences, Chinese Academy of Sciences, Beijing 100085, China \\ ${ }^{\mathrm{b}}$ School of Sustainability, Arizona State University, PO Box 875502, Tempe, AZ 85287-5502, USA \\ ${ }^{\mathrm{c}}$ Beijing Hydrologic Center, Beijing 100089, China
}

\section{A R T I C L E I N F O}

Article history:

Received 3 January 2013

Received in revised form 30 April 2014

Accepted 22 June 2014

Available online 11 July 2014

This manuscript was handled by Andras

Bardossy, Editor-in-Chief, with the

assistance of Ezio Todini, Associate Editor

\section{Keywords:}

Human activities

Precipitation

Streamflow

Monotonic trend

Abrupt change

Regression analysis

\begin{abstract}
S U M M A R Y
In recent decades, the Yongding River in Beijing has ceased to flow due to the impact of climate and anthropogenic factors, which has led to severe environmental degradation. The Beijing government is constructing new freshwater ecosystems on the Yongding River to improve environmental conditions for ecosystem services. Clarification is needed on the influence of precipitation and anthropogenic factors on streamflow decline in Beijing. A hydrological time-series analysis was conducted on recorded streamflow at Guanting Reservoir, Yanchi, and Sanjiadian to estimate the influence of precipitation variability on the drying of the Yongding River in Beijing. From 1980 to 2010, the mean annual rates of streamflow decline were $0.44 \mathrm{~m}^{3} \mathrm{~s}^{-1} \mathrm{yr}^{-1}$ (Guanting), $0.42 \mathrm{~m}^{3} \mathrm{~s}^{-1} \mathrm{yr}^{-1}$ (Yanchi), and $0.03 \mathrm{~m}^{3} \mathrm{~s}^{-1} \mathrm{yr}^{-1}$ (Sanjiadian). The most probable abrupt change-point for annual streamflow was 1999 at Guanting Reservoir and Yanchi, and was 2000 at Sanjiadian. Between the pre-change (1980-1999) and post-change (2000-2010) periods, mean annual streamflow decreased by $68.56 \%$ (Guanting), $66.92 \%$ (Yanchi), and $96.78 \%$ (Sanjiadian). A multiple regression analysis using annual precipitation and streamflow at Guanting, Yanchi, and Sanjiadian showed an insignificant relationship between local precipitation and streamflow in both periods. Next we assessed the potential impact of upstream human activities on downstream flow using: (1) correlation statistics between upstream flow and downstream flow, (2) water abstracted above Sanjiadian, and (3) upstream socioeconomic data. The results suggest upstream human activities are important drivers on downstream flow decline, which could possibly explain the weak relationship between precipitation and streamflow. Further analysis is needed to clarify the influence of upstream water consumption on Guanting Reservoir to advise management on the new freshwater ecosystems along the Yongding River.
\end{abstract}

(c) 2014 Elsevier B.V. All rights reserved.

\section{Introduction}

The Yongding River is Beijing's largest river, commonly known as the city's "Mother River". Humans have impacted the Yongding River for centuries by deforestation, flood control, and water diversions. The headwaters of the Yongding River were historically wooded with large tracts of primary forests, however deforestation from the 13th to 20th centuries caused massive, dangerous floods in Beijing (Li, 2005). Dams were constructed on the Yongding River for flood mitigation, such as the famous Guanting Reservoir built in 1954. In the past 30 years, increased damming and water abstraction have dramatically altered the hydrology of the Yongding River, which experts believe made the Yongding River perennially dry, in particular the lower reaches in Beijing (Yu et al., 2011). Since the late 1970s, the climate regime on the Yongding River has transitioned towards increased drought prevalence (Wang et al.,

\footnotetext{
* Corresponding author. Tel.: +86 106284 9191; fax: +86 1062849816 .

E-mail address: zyouyang@rcees.ac.cn (Z. Ouyang).
}

2011). In the last decade, mean annual precipitation in Beijing was $30 \%$ lower than the long-term historical mean of $585 \mathrm{~mm}$ (Probe, 2010). Streamflow reduction has led to the loss of freshwater ecosystems on the Yongding River, resulting in bare sandy channels, which are considered key contributors to Beijing's dust events (Yue et al., 2006). In Beijing, the channels became gravel mines and dumping grounds for sewage and trash (Dong, 2002). Beijing officials attribute the Yongding River's poor environmental quality to slow economic development in the region. In 2009, the Beijing Water Authority (BWA) approved the construction of the Yongding River Green Ecological Corridor to "ensure water ecosystem services to advance socioeconomic conditions to improve urban livability". The Yongding Corridor seeks to address environmental damages with the construction of six lakes and three functional wetlands, which will bring 130 million $\mathrm{m}^{3}$ of water to the Yongding River. The management targets are: (1) wetland water purification, (2) groundwater recharge and subsidence prevention, (3) elimination of seasonal blowing dust, (4) urban temperature reductions, and (5) aesthetics and recreation. The 
water sources will be reclaimed water from wastewater treatment plants (128 million $\mathrm{m}^{3}$ ), upstream water from Guanting Reservoir (10-30 million $\left.\mathrm{m}^{3}\right)$, and local runoff ( 2 million $\mathrm{m}^{3}$ ) (BWA, 2009). Determining where increasing and decreasing streamflow trends occur, and quantifying the factors driving trends can help authorities manage the Yongding Corridor for the long-term provision of ecosystem services. To prepare for future water allocations, we studied past influences of precipitation and evaluated possible human drivers on streamflow decline in the Yongding River in Beijing.

Concern on the implications of climate change and direct human activities on water resources is growing worldwide. Hydrological processes are increasingly being altered by water infrastructure (Rosenberg et al., 2000), landscape alterations (Gao et al., 2011), and human-induced climate changes from greenhouse gases and aerosols (Barnett et al., 2008). The separation and quantification of climate variation and human impacts on streamflow can be challenging due to the complex interactions between climate, human activities, and hydrological processes. A range of statistical and modeling techniques have been developed to estimate streamflow changes from climate change and human activities (Li et al., 2007; Barnett et al., 2008; Yang and Tian, 2009; Gautam et al., 2010; Ma et al., 2010; Gao et al., 2011). The impacts of climate variability on hydrologic time-series can be estimated using trend analysis (Lettenmaier et al., 1994; Whitfield and Cannon, 2000).

Trend analysis helps to identify the presence of a trend in a hydrologic time-series at different temporal and spatial scales (Lettenmaier et al., 1994; Douglas et al., 2000; Burn and Hag Elnur, 2002; Yue et al., 2003; Birsan et al., 2005, 2012; Hamed, 2008). The most common statistical technique is the non-parametric Mann-Kendall test (Mann, 1945; Kendall, 1975), which is used to identify the existence of monotonic trends in a time-series. The main weakness of the Mann-Kendall statistic is it is designed to detect the monotonic trend, however hydrologic changes can occur both gradually (trend) and abruptly (step-change) (Kundzewicz and Robson, 2004; Mazvimavi and Wolski, 2006). A gradual change is typically slow and constant over time while an abrupt change occurs quickly due to a sudden alteration within a watershed (e.g., reservoir construction, water diversions) (Kundzewicz and Robson, 2000; Smyth et al., 2008). For highly altered watersheds, like the Yongding River, the streamflow record may have periods of abrupt change due to anthropogenic or drought disturbances. An important statistical technique for analyzing climate variability and human activities is calculating change-points, which are commonly determined using the Pettitt test (Pettitt, 1979). Monotonic trend and abrupt change point analyses are often used in combination to characterize a time-series.

After identifying the change-points, three methods can be used to estimate the impact of human activities and climate variability on streamflow, which are hydrologic model simulation, sensitivity analysis, and regression analysis. Hydrologic models can simulate runoff under altered precipitation regimes, land cover alterations, and/or impoundments (Christensen and Lettenmaier, 2006; Guo et al., 2008; Ma et al., 2010). However, simulating runoff using hydrologic models often requires extensive datasets and tedious operations. Hydrologic sensitivity analysis calculates the percent change in mean annual runoff due to changes in mean annual precipitation and potential evapotranspiration (PET) (Dooge et al., 1999; Milly and Dunne, 2002). Jones et al. (2006) estimated the percent change in mean annual runoff under different climate scenarios for 22 Australian catchments by calculating the hydrologic sensitivity of rainfall-runoff models. Chen et al. (2013) used hydrological sensitivity to quantify the effects of climate variability and human activities on runoff in the Kaidu River Basin in northwest China. Regression analysis can determine the correlation between runoff and climate variables (Jiang et al., 2011). Du et al. (2011) used linear regression analysis to separate the impact of human activities and precipitation on streamflow. Zhang et al. (2012) used a runoff model driven by precipitation and evapotranspiration to establish the non-linear relationship between runoff and climate. Jiang et al. (2011) compared all three methods in estimating climate and human activities on runoff from the Laohahe Basin. They found all three methods created consistent estimates of percent change in mean annual runoff from climate variability and human activities. Lastly, the estimates of human activities on streamflow have been evaluated using land use and land cover (Yang and Tian, 2009; Ma et al., 2010) and general historical information (Gao et al., 2011). In this paper, the influences of precipitation on streamflow were estimated at Guanting Reservoir, Yanchi, and Sanjiadian. Precipitation and streamflow trends were characterized using the Mann-Kendall test at all stations. The Pettitt test was used to identify the most probable abrupt change-point in annual runoff from 1980 to 2010 by dividing the runoff time-series into pre- and post-change periods. The statistical influences of precipitation were estimated using the multiple regression analysis method. Subsequently, possible human drivers on streamflow decline were evaluated in three ways by comparing: (1) correlation statistics between upstream flow and downstream flow, (2) Yanchi runoff to water abstracted through the Yongding River Diversion Canal, and (3) upstream socioeconomic trends to inflow and outflow at Guanting Reservoir.

This paper evaluates the influence of precipitation and possible human drivers on streamflow decline of the Yongding River in Beijing from 1980 to 2010 . The main research questions are: what is the influence of local precipitation variability on streamflow decline along the Yongding River in Beijing, and what are the potential human drivers of streamflow decline? The paper objectives are: (1) determine the temporal trends in the precipitation and streamflow time-series; (2) identify the abrupt change-points in streamflow; (3) identify the impact of precipitation changes on streamflow; (4) evaluate potential human drivers using historical information, water abstracted through the Yongding River Diversion Canal, and upstream socioeconomic data.

\section{Materials and methods}

\subsection{Study area}

The Yongding River is $747 \mathrm{~km}$ long with a watershed area of $47,016 \mathrm{~km}^{2}$, and is a major tributary of the Hai River Basin. The Yongding River starts in Shanxi Province flows through Inner Mongolia Autonomous Region and Hebei Province and terminates at Bohai Bay. The headwaters of the Yongding River, located in northern Shanxi Province and northern Hebei Province, are referred to as the Sanggan River, and the headwaters located in the Inner Mongolia Autonomous Region are known as the Yang River. Our study area extends from Guanting Reservoir in Hebei Province to Sanjiadian in Beijing Municipality, stretching between longitudes $115^{\circ} 36^{\prime}-116^{\circ} 13^{\prime} \mathrm{E}$ and latitudes $40^{\circ} 14^{\prime}-39^{\circ} 52^{\prime} \mathrm{N}$ (Fig. 1). The study site covers three hydrological stations: (1) Guanting Reservoir, (2) Yanchi, and (3) Sanjiadian. The study area is defined as the Beijing section of the Yongding River, including the Guanting Reservoir, but excluding Yanqing since the majority of hydrologic stations are in Beijing Municipality.

Beijing has a seasonal temperate and semiarid continental monsoonal climate. The average annual precipitation spans $550-660 \mathrm{~mm}$ in which roughly $85 \%$ of the rainfall occurs from June to September. The major land use types in the Yongding River Basin are forest, grassland, cropland, urban, and industrial.

For each section we conceptualized the water balance to identify the main drivers in the system. Fig. 2 outlines our hypothesis 

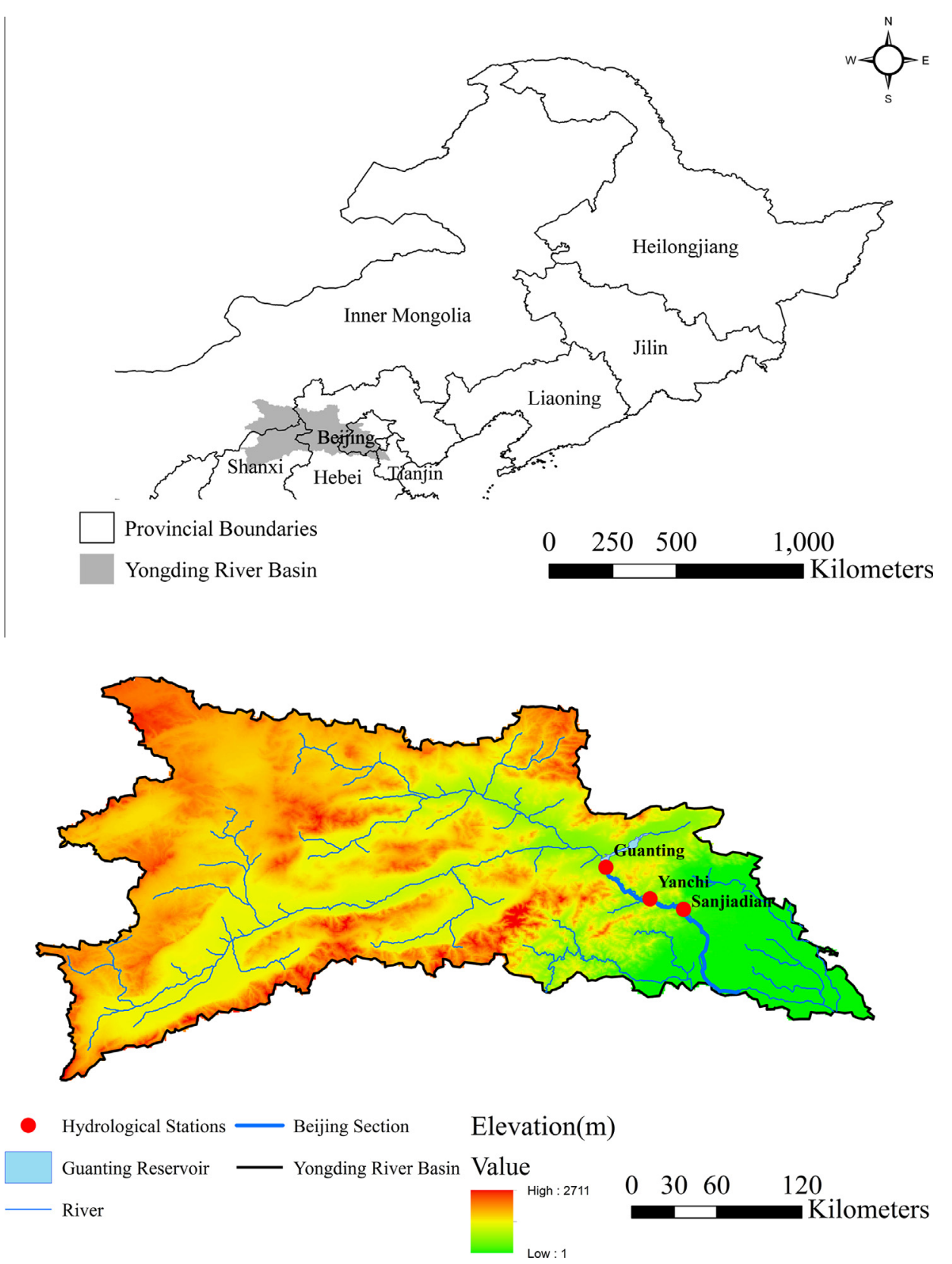

Fig. 1. Map of the study area in the Yongding River Basin. The three stations were: Guanting Reservoir, Yanchi, and Sanjiadian.

of the upstream and downstream relationship in the study area. Outflow from Guanting Reservoir controls Yanchi streamflow and subsequent Sanjiadian streamflow. The primary hydrologic inputs are precipitation and upstream runoff while the removal factors are evapotranspiration (ET), groundwater recharge, and human activities (e.g. water abstraction, groundwater pumping, and land cover changes). For the Yongding River, the two main drivers of streamflow decline were assumed to be precipitation and human activities in which other environmental factors, like evapotranspiration and air temperature, were not evaluated. Our analysis focused on these two drivers because drought and water abstraction for human activities are considered the main causes of streamflow decline on the Yongding River in the peer-reviewed literature (Yang and Zhang, 2005; Cheng et al., 2001; Liu et al., 2011). In particular we noted the Yongding River Diversion Canal, located below Yanchi but above Sanjiadian station because it is an important water loss factor impacting downstream sections below
Sanjiadian. We evaluated the influence of precipitation at each station then tried to identify potential upstream human drivers on downstream flow decline.

\subsection{Data}

Monthly precipitation and monthly streamflow datasets from 1980 to 2010 were used from Guanting Reservoir, Yanchi, and Sanjiadian stations. Streamflow data were average monthly measured flow rates at each station from the Beijing Hydrologic Center; for Guanting Reservoir inflow data were used from the Beijing Water Authority. Data on water abstracted through the Yongding River Diversion Canal from 1981 to 2010 were used from the Beijing Water Authority to understand the drying below Sanjiadian. Socioeconomic data from 1980 to 2010 for 31 counties above Guanting Reservoir were selected, representing four key human activity indicators known to influence water use (Gleick, 2003): (1) total 


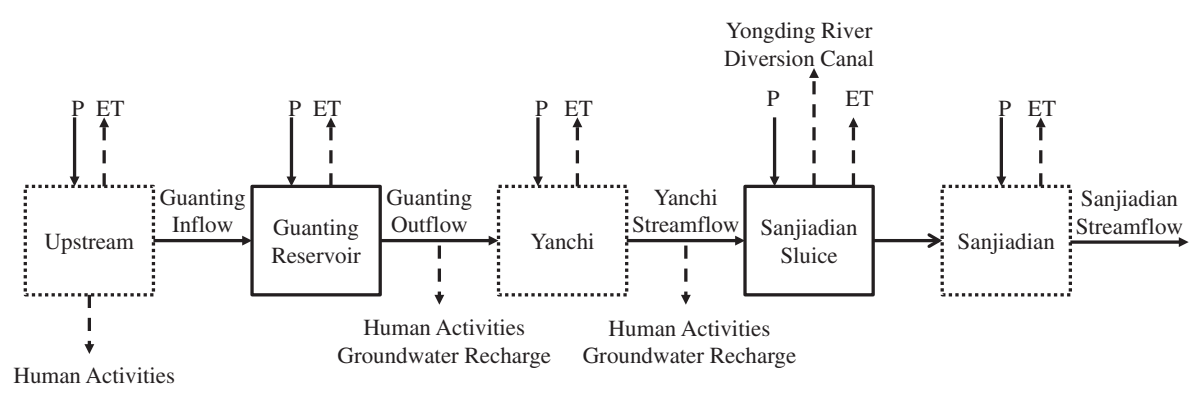

Upstream

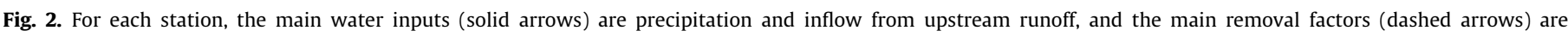

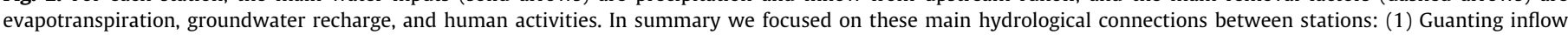

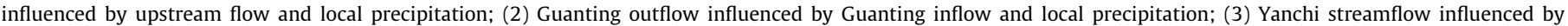

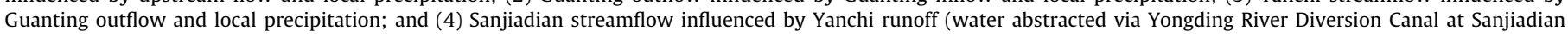
sluice) and local precipitation.

population, (2) GDP (gross domestic product) per capita (CNY), (3) irrigation area (ha), and (4) grain production (t).

\subsection{Methods}

\subsubsection{Monotonic trend}

Many studies use the Mann-Kendall test assuming recorded observations are serially independent despite the frequent presence of serial correlation in hydrological time-series (Yue and Wang, 2002). Von Storch (1995) found positive serial correlation within a time-series can increase the possibility of Type I errorsthe rejection of a 'true' null hypothesis of no trend. Hence one should first eliminate the influence of serial correlation before conducting the Mann-Kendall monotonic trend test by pre-whitening (von Storch, 1995). A modified pre-whitening method (trend-free pre-whitening) (Yue et al., 2002) was applied to eliminate the effect of serial correlation on monthly and annual data for each station. The Theil-Sen approach (Theil, 1950; Sen, 1968) was used to determine the magnitude of the trends in precipitation and streamflow.

\subsubsection{Change-point analysis}

Identification of change-points is an important statistical method in studying the effects of climate variability and human activities on runoff (Jiang et al., 2011). The Pettitt rank-based approach was used to determine the most probable change-point in the streamflow time-series (Pettitt, 1979). This test is considered robust to changes in distributional form when the location changes, and has shown to possess greater statistical power compared to other tests like the Wilcoxon-Mann-Whitney (Kundzewicz and Robson, 2004; Mazvimavi and Wolski, 2006). Also it is useful to detect a change in the median when the time of change is unknown (Pettitt, 1979; Kundzewicz and Robson, 2004; Mazvimavi and Wolski, 2006). Consider a time-series $x_{t}(1 \leqslant t \leqslant n)$, the Pettitt test is an adaptation of the Mann-Whitney statistic $U_{t, n}$ that tests whether two sample sets $\left(x_{1}, x_{2}, \ldots, x_{t}\right)$ and $\left(x_{t+1}, x_{t+2}, \ldots, x_{n}\right)$ are from the same population. The test statistic $U_{t, n}$ is given by:

$U_{t, n}=\sum_{i=1}^{t} \sum_{j=t+1}^{n} \operatorname{sgn}\left(x_{i}-x_{j}\right)$

where

$$
\operatorname{sgn}\left(x_{i}-x_{j}\right)= \begin{cases}+1 & \text { if } x_{i}-x_{j}>0 \\ 0 & \text { if } x_{i}-x_{j}=0 \\ -1 & \text { if } x_{i}-x_{j}<0\end{cases}
$$

This test statistic counts the number of times a member of the first sample exceeds a member of the second sample. The test statistic identifies the most probable change-point where the $U_{t, n}$ is the maximum value: $K_{t}=\max _{1 \leqslant t \leqslant n}\left|U_{t, n}\right|$ and the associated probability is given using Monte Carlo resamplings based on XLSTAT software. For the Pettitt test the null hypothesis is the absence of an abrupt change-point over time and the alternative hypothesis is a change in distribution at time $t$. If a significant change in median exists at time $t$, the time series is divided into two sub-periods (pre- and post-change) at the shift point (Mazvimavi and Wolski, 2006).

\subsubsection{Regression analysis}

Multiple regression analysis was used to identify the influence of precipitation variability and time effect on runoff. Based on the results of the Pettitt test, the runoff data at each station were divided into two periods: pre-change and post-change. The multiple regression analysis was conducted using Eviews 6.0 to estimate whether the intercept and regression coefficient remained the same in the two time periods by including time as a dummy variable (one for pre-change period, and zero for post change-period). We evaluated the multiplicative effect of the dummy variable on the relationship between precipitation and runoff. An insignificant relationship at the significance level of 0.05 suggests the influence of precipitation on runoff remains unchanged across the whole period. If the relationship is insignificant then the analyst would exclude the multiplicative effect of the dummy variable from the regression analysis. A new multiple regression analysis is then conducted to identify whether precipitation significantly influenced runoff across the whole period (1980-2010), and the impact of time on changes in runoff. The final multiple regression analysis consisted of:

$\log \left(Y_{i}+2\right)=\beta_{0}+\beta_{1} * D_{i}+\beta_{2} * X_{i}+\beta_{3} * D_{i} * X_{i}+\varepsilon_{i}$

where $Y_{i}$ is annual runoff (1980-2010), $X_{i}$ is annual precipitation (1980-2010), $\varepsilon_{i}$ is the random error, and $D_{i}$ is a dummy variable

$D_{i}= \begin{cases}1 & X_{i} \text { belongs to the pre-change period } \\ 0 & X_{i} \text { belongs to the post-change period }\end{cases}$

\subsubsection{Correlation analysis}

Correlation statistics were used to determine the hydrological connectivity between upstream and downstream. A correlation matrix compared Guanting Reservoir inflow and outflow at all stations for the pre- and post-change periods. The correlation 
coefficients were used as indicators of hydrologic connectivity of relationships illustrated in Fig. 2. Higher coefficients were interpreted as stronger possible connections, thus indicating in our evaluation upstream influence on downstream. If the influence of upstream flow on downstream flow was present in both periods then upstream flow variability was likely the primary reason for the decline in downstream flow.

\subsubsection{Human activities: water abstracted through Yongding River} Diversion Canal and upstream human activities

First, we assessed the influence of local human activities on Sanjiadian runoff by determining: (1) the water abstraction trend of the Yongding River Diversion Canal from 1981 to 2010 and (2) the difference between Yanchi runoff and water abstracted through the Yongding River Diversion Canal. Second, we qualitatively compared the graphic trends of four key socioeconomic indicators of upstream human activities (representing population growth, agriculture, and development) to Guanting Reservoir inflow and outflow from 1980 to 2010. These indicators were selected because they are known predictors of water use (Gleick, 2003). In particular we focused on agriculture because agricultural water consumption accounted for approximately 56\% of available upstream water resources in 1999 (Yang and Zhang, 2005).

\section{Results}

\subsection{Trend analysis}

\subsubsection{Monotonic trends for annual precipitation}

From 1980 to 2010, the mean annual precipitation for each of the three hydrological stations was 369.99, 442.94, and $552.21 \mathrm{~mm}$. At all stations the average annual precipitation in the 1980s was similar to the 2000s, however the 1990s marked an increase in precipitation compared to the 1980 s and 2000s (Fig. 3). In the 2000s, total annual precipitation declined by $10.34-14.86 \%$ compared to the 1990 s at the three stations. For all stations, total annual precipitation showed statistically insignificant trends $(p>0.05)$.

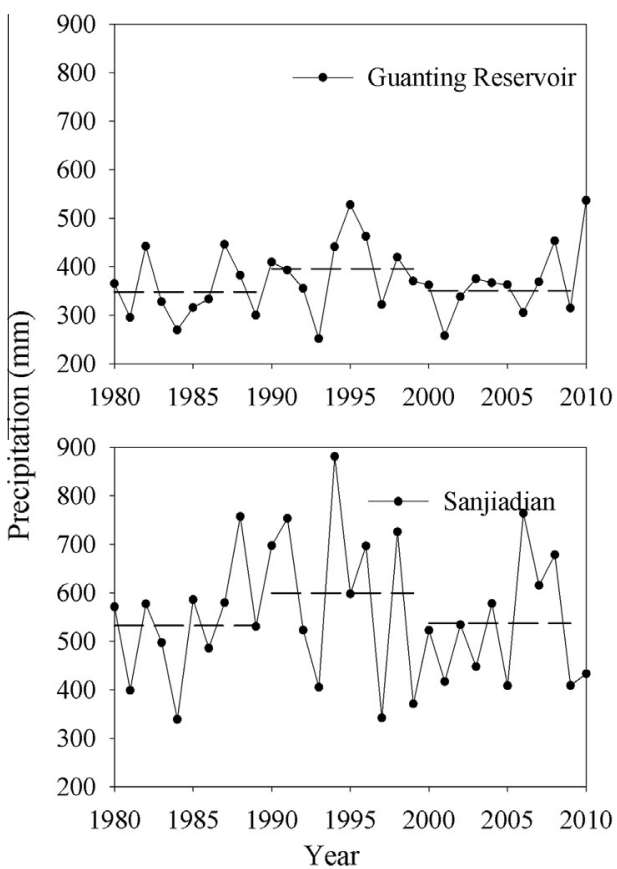

3.1.2. Monotonic trends for monthly and annual streamflow

The trend-free pre-whitening Mann-Kendall tests indicated downward trends for annual and monthly streamflow at all stations. The downward trend of annual streamflow was significant for all stations. The average annual rate of streamflow decline for each station was calculated to be $0.44 \mathrm{~m}^{3} \mathrm{~s}^{-1} \mathrm{yr}^{-1}$ (Guanting Reservoir), $0.42 \mathrm{~m}^{3} \mathrm{~s}^{-1} \mathrm{yr}^{-1}$ (Yanchi), and $0.03 \mathrm{~m}^{3} \mathrm{~s}^{-1} \mathrm{yr}^{-1}$ (Sanjiadian). The monthly streamflow time-series at Guanting Reservoir and Yanchi exhibited significant downward trends $(p<0.01)$, and for Sanjiadian more than half of the monthly time-series showed an insignificant downward trend (Table 1).

\subsubsection{Change-point analysis of streamflow}

For all stations the Mann-Kendall tests showed significant decreasing trends in streamflow, thus the Pettitt test was applied to detect the most probable change-point in the streamflow time-series at each station. The Pettitt test showed the significant change-point for annual streamflow at Guanting Reservoir and Yanchi was $1999\left(K_{t}=210, p<0.01\right)$, and was $2000\left(K_{t}=170\right.$, $p<0.01$ ) for Sanjiadian (Fig. 4).

Based on the abrupt-change analysis, we divided the time-series into two periods at each station. The most probable abrupt change-point occurred nearly at the same time at the three stations, thus we chose the pre-change period as 1980-1999 and the post-change period as 2000-2010. Table 2 provides the summary statistics for the annual and monthly streamflow series for both periods at all stations. For the pre-change period, the mean annual streamflows were $14.23 \mathrm{~m}^{3} \mathrm{~s}^{-1}$ (Guanting Reservoir), $15.03 \mathrm{~m}^{3} \mathrm{~s}^{-1}$ (Yanchi), and $2.35 \mathrm{~m}^{3} \mathrm{~s}^{-1}$ (Sanjiadian). For the postchange period, the mean annual streamflows were $4.48 \mathrm{~m}^{3} \mathrm{~s}^{-1}$ (Guanting Reservoir), $4.97 \mathrm{~m}^{3} \mathrm{~s}^{-1}$ (Yanchi), and $0.08 \mathrm{~m}^{3} \mathrm{~s}^{-1}$ (Sanjiadian). Between the pre- and post-change periods, the mean annual streamflow decreased by 68.56\% (Guanting Reservoir), 66.92\% (Yanchi), and 96.78\% (Sanjiadian).

\subsection{Impacts of precipitation on runoff and hydrologic connections}

We conducted a multiple regression analysis to identify the influence of precipitation and the time effect of precipitation on

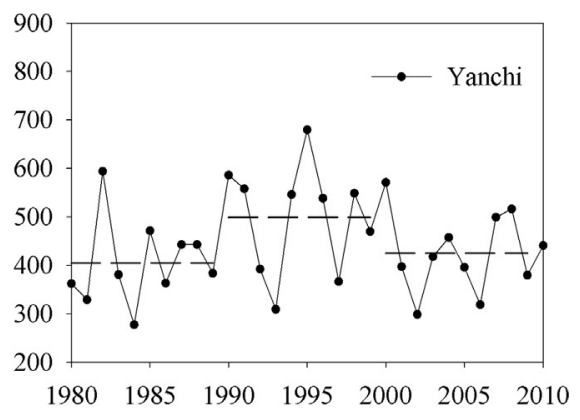


Table 1

The Sen's slope and TFPW Mann-Kendall test for annual streamflow and monthly streamflow at Guanting Reservoir, Yanchi, and Sanjiadian.

\begin{tabular}{|c|c|c|c|c|c|c|}
\hline \multirow[t]{2}{*}{ Season } & \multicolumn{2}{|l|}{ Guanting Reservoir } & \multicolumn{2}{|l|}{ Yanchi } & \multicolumn{2}{|l|}{ Sanjiadian } \\
\hline & Slope $\left(\mathrm{m}^{3} / \mathrm{s} /\right.$ year$)$ & $Z$ & Slope $\left(\mathrm{m}^{3} / \mathrm{s} /\right.$ year $)$ & $Z$ & Slope $\left(\mathrm{m}^{3} / \mathrm{s} /\right.$ year $)$ & $Z$ \\
\hline January & -0.38 & $-4.57^{* *}$ & -0.39 & $-4.51^{* *}$ & $0^{*}$ & -0.93 \\
\hline February & -0.41 & $-4.83^{* *}$ & -0.42 & $-5.12^{* *}$ & $0^{*}$ & -1.29 \\
\hline March & -0.46 & $-5.2^{* *}$ & -0.45 & $-4.69^{* *}$ & $0^{*}$ & -0.84 \\
\hline April & -0.48 & $-5.17^{* *}$ & -0.42 & $-5.1^{* * *}$ & $0^{*}$ & $-2.88^{* *}$ \\
\hline May & -0.46 & $-3.82^{* *}$ & -0.48 & $-3.89^{* *}$ & $0^{*}$ & $-3.30^{* *}$ \\
\hline June & -0.97 & $-4.73^{* *}$ & -0.9 & $-4.62^{* *}$ & $0^{*}$ & $-3.75^{* *}$ \\
\hline July & -0.44 & $-3.57^{* *}$ & -0.5 & $-3.66^{* *}$ & $0^{*}$ & $-2.63^{* *}$ \\
\hline August & -0.39 & $-3.18^{* *}$ & -0.45 & $-3.81^{* *}$ & $0^{*}$ & $-2.29^{* * *}$ \\
\hline September & -0.29 & $-2.81^{* *}$ & -0.3 & $-3.42^{* *}$ & $0^{*}$ & -1.93 \\
\hline October & -0.33 & $-3.78^{* *}$ & -0.32 & $-3.39^{* *}$ & $0^{*}$ & -1.14 \\
\hline November & -0.34 & $-4.32^{* *}$ & -0.33 & $-4.17^{* *}$ & $0^{*}$ & -1.95 \\
\hline December & -0.41 & $-4.76^{* *}$ & -0.38 & $-4.95^{* *}$ & $0^{*}$ & -0.8 \\
\hline Ann & -0.44 & $-5.07^{* *}$ & -0.42 & $-4.78^{* *}$ & -0.03 & $-3.41^{* *}$ \\
\hline
\end{tabular}

* Zero value of slope in each month is because of zero streamflow in monthly data in recent years.

** Significant at the 0.01 level.

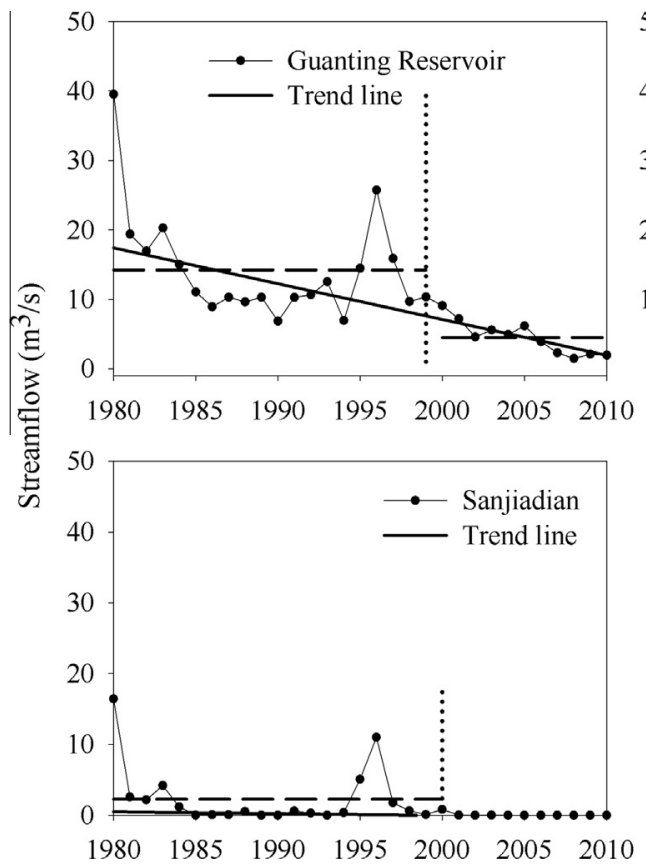

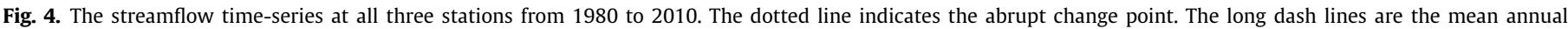
streamflow for the pre-change and post-change periods.

Table 2

The summary statistics of the annual and monthly streamflow data for two sub-periods at Guanting Reservoir, Yanchi, and Sanjiadian.

\begin{tabular}{|c|c|c|c|c|c|c|c|c|c|c|c|c|}
\hline \multirow[t]{3}{*}{ Season } & \multicolumn{4}{|c|}{ Guanting Reservoir } & \multicolumn{4}{|l|}{ Yanchi } & \multicolumn{4}{|l|}{ Sanjiadian } \\
\hline & \multicolumn{2}{|l|}{ 1980-1999 } & \multicolumn{2}{|l|}{ 2000-2010 } & \multicolumn{2}{|l|}{ 1980-1999 } & \multicolumn{2}{|l|}{ 2000-2010 } & \multicolumn{2}{|l|}{ 1980-1999 } & \multicolumn{2}{|l|}{ 2000-2010 } \\
\hline & Mean $\left(\mathrm{m}^{3} / \mathrm{s}\right)$ & S.D. & Mean $\left(\mathrm{m}^{3} / \mathrm{s}\right)$ & S.D. & Mean $\left(\mathrm{m}^{3} / \mathrm{s}\right)$ & S.D. & Mean $\left(\mathrm{m}^{3} / \mathrm{s}\right)$ & S.D. & Mean $\left(\mathrm{m}^{3} / \mathrm{s}\right)$ & S.D. & Mean $\left(\mathrm{m}^{3} / \mathrm{s}\right)$ & S.D. \\
\hline January & 11.91 & 7.58 & 3.28 & 1.36 & 12.54 & 7.01 & 4.11 & 1.70 & 1.06 & 4.36 & 0.00 & 0.00 \\
\hline February & 10.37 & 3.72 & 2.93 & 1.38 & 11.05 & 3.60 & 3.58 & 1.46 & 0.04 & 0.13 & 0.00 & 0.00 \\
\hline March & 11.45 & 4.46 & 3.52 & 1.93 & 12.25 & 4.47 & 4.05 & 1.82 & 0.23 & 0.89 & 0.09 & 0.27 \\
\hline April & 15.35 & 14.54 & 4.96 & 2.90 & 15.44 & 14.41 & 5.24 & 2.84 & 2.74 & 9.64 & 0.04 & 0.13 \\
\hline May & 19.48 & 19.60 & 5.44 & 3.49 & 20.63 & 21.24 & 5.57 & 3.29 & 5.48 & 12.87 & 0.00 & 0.00 \\
\hline June & 24.57 & 20.67 & 5.44 & 3.17 & 25.28 & 21.86 & 5.93 & 3.43 & 5.70 & 12.84 & 0.00 & 0.00 \\
\hline July & 16.66 & 17.61 & 5.04 & 2.65 & 18.26 & 17.85 & 5.97 & 3.17 & 3.59 & 7.87 & 0.77 & 2.55 \\
\hline August & 13.00 & 9.74 & 5.29 & 3.29 & 14.72 & 9.69 & 5.40 & 2.86 & 2.65 & 7.15 & 0.01 & 0.02 \\
\hline September & 12.26 & 10.18 & 6.26 & 4.60 & 13.18 & 9.80 & 6.24 & 4.58 & 1.85 & 5.46 & 0.00 & 0.00 \\
\hline October & 12.51 & 8.29 & 4.28 & 2.62 & 13.29 & 7.76 & 5.41 & 4.14 & 1.98 & 5.98 & 0.00 & 0.00 \\
\hline November & 11.30 & 7.24 & 4.25 & 3.02 & 11.63 & 7.10 & 4.52 & 3.03 & 1.48 & 3.86 & 0.00 & 0.00 \\
\hline December & 11.92 & 9.40 & 3.01 & 1.62 & 12.14 & 8.85 & 3.66 & 1.68 & 1.38 & 5.99 & 0.00 & 0.00 \\
\hline Ann & 14.23 & 7.65 & 4.48 & 2.42 & 15.03 & 7.77 & 4.97 & 2.64 & 2.35 & 4.24 & 0.08 & 0.24 \\
\hline
\end{tabular}

S.D. $=$ Standard Deviation. 
Table 3

Multiple regression analysis presenting the influence of precipitation variability on runoff with time as a dummy variable at Guanting Reservoir, Yanchi, and Sanjiadian.

\begin{tabular}{|c|c|c|c|c|c|}
\hline & & $\beta$ & SE & $t$ & $P$ \\
\hline \multicolumn{6}{|c|}{ Multiplicative effect and variables } \\
\hline Guanting & Precipitation & -0.001 & 0.001 & -1.243 & 0.225 \\
\hline \multirow[t]{3}{*}{ Reservoir } & Time & 0.153 & 0.564 & 0.272 & 0.788 \\
\hline & Time * Precipitation & 0.001 & 0.002 & 0.838 & 0.409 \\
\hline & Constant & 1.753 & 0.449 & 3.907 & 0.001 \\
\hline \multirow[t]{4}{*}{ Yanchi } & Precipitation & 0.000 & 0.001 & 0.333 & 0.742 \\
\hline & Time & 1.048 & 0.543 & 1.930 & 0.064 \\
\hline & Time * Precipitation & -0.001 & 0.001 & -0.799 & 0.431 \\
\hline & Constant & 1.095 & 0.470 & 2.333 & 0.027 \\
\hline \multirow{4}{*}{ Sanjiadian } & Precipitation & 0.000 & 0.001 & -0.006 & 0.996 \\
\hline & Time & 0.184 & 0.502 & 0.366 & 0.717 \\
\hline & Time * Precipitation & 0.000 & 0.001 & 0.093 & 0.927 \\
\hline & Constant & 0.707 & 0.426 & 1.658 & 0.109 \\
\hline \multicolumn{6}{|c|}{ Non-multiplicative effect and variables } \\
\hline Guanting & Precipitation & -0.001 & 0.001 & -0.958 & 0.346 \\
\hline \multirow[t]{2}{*}{ Reservoir } & Time & 0.618 & 0.106 & 5.843 & 0.000 \\
\hline & Constant & 1.458 & 0.277 & 5.256 & 0.000 \\
\hline \multirow[t]{3}{*}{ Yanchi } & Precipitation & 0.000 & 0.001 & -0.782 & 0.441 \\
\hline & Time & 0.622 & 0.106 & 5.891 & 0.000 \\
\hline & Constant & 1.420 & 0.234 & 6.067 & 0.000 \\
\hline \multirow[t]{3}{*}{ Sanjiadian } & Precipitation & 0.000 & 0.000 & 0.153 & 0.879 \\
\hline & Time & 0.229 & 0.112 & 2.050 & 0.050 \\
\hline & Constant & 0.673 & 0.222 & 3.033 & 0.005 \\
\hline
\end{tabular}

runoff where time was a dummy variable (Table 3). For all the three stations, the multiplicative effect of the dummy variable was insignificant $(p>0.05)$. This result led us to exclude the multiplicative effect of the dummy variable from the regression equation. In the regression equation with no multiplicative effect of the dummy variable, the influence of precipitation on runoff was insignificant $(p>0.05)$, however the effect of time as a dummy variable on runoff was significant $(p<0.01)$, which suggests precipitation had little influence on runoff at all three stations from 1980 to 2010.

For the pre-change period, the correlation coefficients among all stations (including Guanting inflow) were statistically significant $(p<0.01)$. For the post-change period, the correlation coefficients were significant for Guanting inflow between Guanting outflow and Yanchi outflow $(p<0.01)$. Also the correlation coefficient between Guanting outflow and Yanchi outflow was significant $(p<0.01)$ in the post-change period (Table 4$)$. The results suggest the presence of connections between upstream flow and downstream flow, thereby indicating the likely influence of upstream flow change on downstream flow change.

\subsection{Human activities: water abstraction and upstream socioeconomic indicators}

\subsubsection{Water abstraction}

From 1981 to 2010, water abstraction through the Yongding River Diversion Canal showed a significant downward trend with a $Z$-value of $-4.96(p<0.01)$. The difference between Yanchi runoff and water abstracted through the Yongding River Diversion Canal differed between the pre- and post-change periods (Fig. 5). In the pre-change period, there were more fluctuations, such as in the early-1980s and late-1990s when Yanchi runoff was greater than water abstracted because Guanting outflow was at higher levels. However in the post-change period, the difference between Yanchi runoff and water abstracted through the Yongding River Diversion Canal was relatively stable, near zero, indicating almost all Yanchi runoff was removed through the Yongding River Diversion Canal prior to reaching Sanjiadian.

\subsubsection{Upstream human activities}

We visually compared the graphical trends of upstream human activities to Guanting inflow and outflow trends from 1980 to 2010 at 5-year intervals (Fig. 6). The Guanting inflow and outflow curves mirrored each other, only differing slightly after 2000 with a steeper decline in outflow than inflow. Total population showed a steady upward trend, and GDP per capita showed a positive trend across the time-series (1995-2010) with a rapid increase in the slope after 2000, which matched a sharper decline in Guanting outflow. Irrigation area decreased in 1985 then peaked in 1995 (23.47\% greater than 1985 ) followed by a relatively stable trend. Grain production rose steeply from 1980 to 1990 then dipped in 1995, matching the rise and fall in Guanting inflow and outflow, followed by a rapid increase from 2000 to 2010 when Guanting inflow and outflow fell to their lowest levels.

\section{Discussion}

\subsection{Precipitation and streamflow trends}

The annual precipitation time-series from 1980 to 2010 showed an insignificant positive trend for all three stations, which is likely due to precipitation peaks in the mid-1990s. Mean annual precipitation was lower in the 1980 s and 2000 s compared to the 1990s. The annual streamflow time-series for all stations exhibited significant downward trends, however the mean annual rate was greatest at Guanting Reservoir and lowest at Sanjiadian. The relative stable precipitation regimes in comparison to the significant declining streamflow trends at the three stations suggest precipitation had a minor influence on the decline in mean annual streamflow in the post-change period. However the most probable change-points in the streamflow time-series at all stations match the start years of Beijing's most recent drought (Table 5). From 1980 to 2010, Beijing suffered two official droughts (defined as significant reduction in precipitation from the mean long-term value of $585 \mathrm{~mm}$ ) in: (1) the 1980s and (2) 1999-2007 (Probe, 2010). Mean annual precipitation at the three stations from 1980 to 2010 were 36.8\% (Guanting Reservoir), 24.3\% (Yanchi), and 5.6\% (Sanjiadian) lower than the long-term mean annual precipitation in Beijing. Precipitation may not have been a significant major factor, but it still contributed to the dramatic decline in annual streamflow in the post-change period when Beijing suffered its most recent climatic drought.

Table 4

Correlation matrix comparing inflow to Guanting Reservoir and outflow at all stations for the pre-change (1980-1999) and post-change (2000-2010) periods.

\begin{tabular}{|c|c|c|c|c|c|c|c|c|}
\hline & \multicolumn{2}{|l|}{ Inflow } & \multicolumn{2}{|l|}{ Guanting } & \multicolumn{2}{|l|}{ Yanchi } & \multicolumn{2}{|l|}{ Sanjiadian } \\
\hline & 1980-1999 & $2000-2010$ & 1980-1999 & 2000-2010 & 1980-1999 & 2000-2010 & 1980-1999 & 2000-2010 \\
\hline Inflow & 1 & 1 & $0.793^{*}$ & $0.799^{*}$ & $0.777^{*}$ & $0.844^{*}$ & $0.834^{*}$ & \\
\hline Guanting & & & 1 & 1 & $0.996^{*}$ & $0.988^{*}$ & $0.941^{*}$ & \\
\hline Yanchi & & & & & 1 & 1 & $0.931^{*}$ & \\
\hline Sanjiadian & & & & & & & 1 & \\
\hline
\end{tabular}

Note the missing entries in the last column are because of zero flow at Sanjiadian in the post-change period.

Correlation is significant at the 0.01 level. 


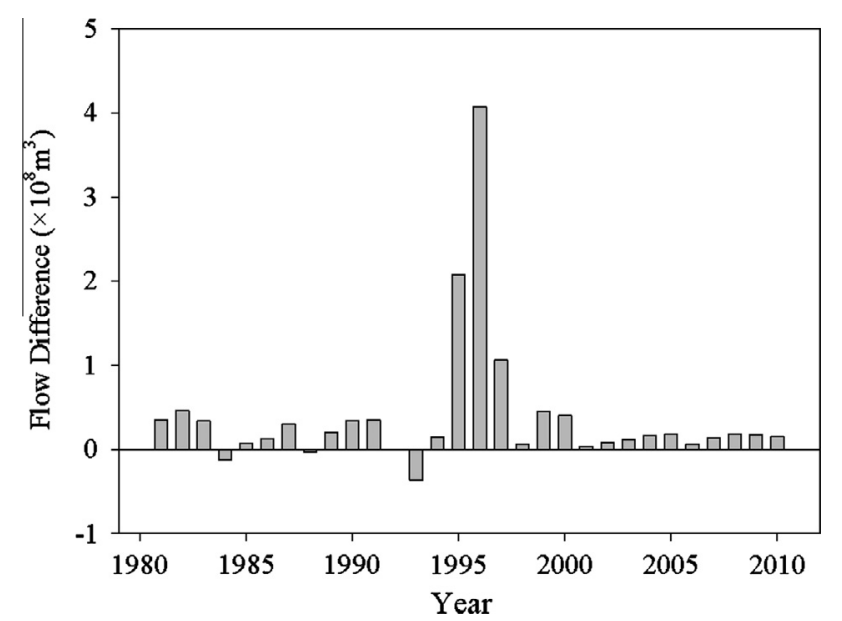

Fig. 5. The difference between Yanchi runoff and water abstracted through the Yongding River Diversion Canal from 1981 to 2010.

\subsection{Influence of precipitation on streamflow decline and potential human drivers}

From 1980 to 2010, the main cause of streamflow decline on the Yongding River Basin was likely human activities. First the multiple regression analysis showed an insignificant relationship between local precipitation and streamflow at all stations in both the pre- and post-change periods. Next we evaluated the possible influence of human activities by first determining the effect of upstream flow on downstream flow, and second comparing flow trends to upstream socioeconomic trends.

The hydrologic connectivity and water abstraction results suggest upstream flow reduction is likely the main cause in downstream flow decline. The average annual inflow at Guanting Reservoir declined in the post-change period compared to the pre-change period, and Guanting inflow was significantly, positively correlated to Guanting and Yanchi outflows. These results suggest upstream flow impacted Guanting Reservoir inflow, which then likely influenced downstream outflow in the lower reaches (Fig. 2). Furthermore, the quantity of water abstracted through the Yongding River Diversion Canal significantly decreased from 1981 to 2010, however the difference between Yanchi runoff and water abstracted differed between the pre- and post-change periods. In the pre-change period, there were more fluctuations in the difference where in the early-1980s and late-1990s Yanchi runoff was greater than water abstracted because Guanting outflow was at higher levels. The higher Yanchi runoff in the early-1980s and late-1990s resulted in streamflow at Sanjiadian during these periods. However in the post-change period, the difference between Yanchi runoff and water abstracted was near zero, which resulted in zero streamflow at Sanjiadian. Despite the drying of Sanjiadian from 1980 to 2010, we identified an abrupt change point in the streamflow record separating 1980-1999 and 20002010 because of higher Guanting outflow in 1980-1999. This result suggests the upstream flow reductions in the post-change period, likely from increased human activities, reduced Guanting outflow. The decline in Guanting outflow reduced Yanchi runoff, which caused the prolonged zero flow below Sanjiadian in the postchange period.

Population growth, agriculture, and development are all important factors contributing to upstream water consumption in the Yongding River (Cheng et al., 2001). The total population, from 1990 to 2010, in the counties upstream of Guanting Reservoir, increased by $11 \%$ from 7.3 million to 8.2 million. The substantial population growth likely led to increased domestic water demand across the region. Another important factor is agriculture shown in the opposite trends between Guanting inflow and outflow and grain production. In 1995 grain production dropped, which was matched by a rise in Guanting inflow and outflow. Subsequently, from 2000 to 2010 grain production rose rapidly with a $23 \%$ increase while Guanting inflow and outflow during the same period dropped to its lowest levels. Interestingly, however, irrigation area peaked in 1995 then stabilized, which potentially suggests increased water use throughout the grain production process was not fully captured by irrigation area.
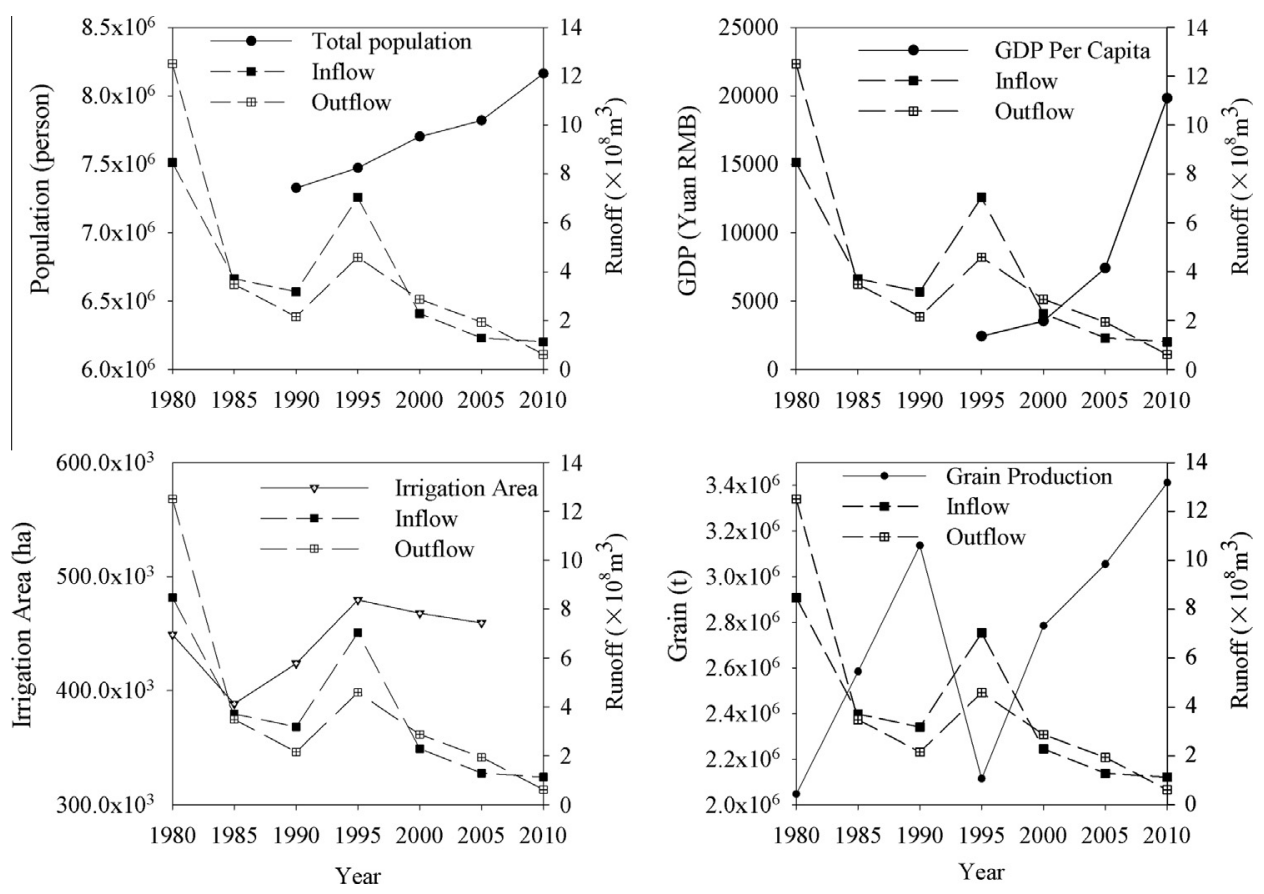

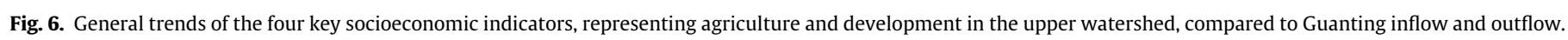


Table 5

A timeline of major events at Guanting Reservoir and the Beijing section of the Yongding River from 1980 to 2010.

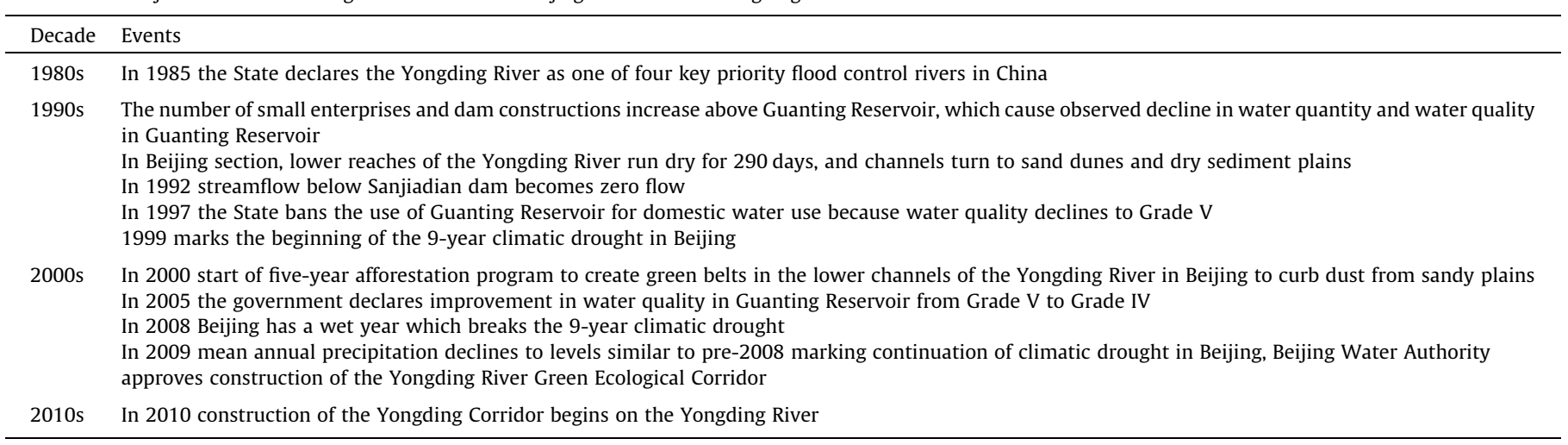

To assess economic growth in the upper basin, we used GDP per capita as our proxy, which showed the greatest rise from 1995 to 2010 among all indicators with an increase of approximately $720 \%$. Our socioeconomic dataset possessed no specific variables on the industrial or urban sectors. In the Yongding River Basin, the primary industrial water consumers are power, metallurgy, chemical, and food production (Yang and Zhang, 2005). Cheng et al. (2001) identified the coal industry as a major upstream water consumer responsible for increased surfacewater and groundwater use. The upper reaches of the Yongding River are located near Datong in Shanxi Province, which is home to one of the largest coal deposits in China. The main economic industry in Datong is coal mining, which is highly water intensive. Nearly 300 small and large reservoirs have been constructed above Guanting Reservoir to support increased upstream water demand for agriculture, industry, and urban demands (Feng, 2005). The hydrological connectivity results and historical information suggest increased agricultural production and development were likely the main upstream contributors to downstream flow decline on the Yongding River in the post-change period. However we recognize the limits of a qualitative analysis using socioeconomic indicators not direct water use, therefore further analysis is needed linking water consumption to streamflow decline on the Yongding River.

Our study results suggest the primary factor on streamflow decline on the Yongding River is likely upstream human activities compared to precipitation. From 1980 to 2010, there was less hydrologic connectivity between upstream and downstream at Sanjiadian. In the early-1990s below Sanjiadian zero flow started appearing, which turned into persistently dry river beds after 2000 because of reduced Guanting outflow (Table 5). The drying at Sanjiadian can likely be attributed to reduced upstream runoff possibly from increased upstream human activities.

\subsection{Guanting Reservoir and Yongding Corridor}

The Beijing government will construct six lakes and three wetlands on the lower reaches of the Yongding River to enhance ecosystem services in the region. The new ecosystems are critical to Beijing's sustainability agenda where green infrastructure is used to create an eco-city (BWA, 2009). To obtain the environmental and social targets, however, requires understanding the vulnerabilities and trade-offs of different water sources needed to sustain the Yongding Corridor. The Beijing Water Authority plans to obtain 10-30 million $\mathrm{m}^{3}$ of water inputs from the Guanting Reservoir. From 2000 to 2010 the mean annual streamflow at Sanjiadian was $0.08 \mathrm{~m}^{3} \mathrm{~s}^{-1}$, yet the engineers of the Yongding Corridor want the streamflow in the lower reaches below Sanjiadian to range from 0.46 to $1.74 \mathrm{~m}^{3} \mathrm{~s}^{-1}$ (Gao, 2012). In 2011, during the first-year of operation, the Guanting Reservoir was the main water source for four new lakes, providing 7.5 million $\mathrm{m}^{3}$ of water (Lu et al., 2012). The water circulation system incurred problems, which led to poor water quality in certain sections of the Yongding Corridor due to low water levels (Lu et al., 2012). We speculate the low water levels resulted from relying on the Guanting Reservoir, which likely cannot meet the full water demands of the Yongding Corridor. The Guanting Reservoir is the main proximal water source, requiring less energy than other sources to bring water to the lakes and wetlands. The engineers have planned to use mainly reclaimed water $\left(128\right.$ million $\left.\mathrm{m}^{3}\right)$, which will have greater energy costs that will produce different trade-offs to the region. Weighing the vulnerabilities and trade-offs of the water portfolio will be important in the long-term success of the Yongding Corridor.

\subsection{Limitations}

The results should be interpreted in the context of three limitations, which are: (1) the short-time frame of the time-series analysis; (2) use of inference to identify potentially important socioeconomic drivers of upstream water use; (3) not calculating evapotranspiration and upstream precipitation. The study focused on identifying the influence of local precipitation on runoff at three hydrological stations, and qualitatively evaluating the impact of potential human drivers. We used a thirty-year, monthly time-series of precipitation and streamflow, which unfortunately did not allow us to compare recent decadal changes to long-term precipitation and streamflow patterns on the Yongding River. Our result of an insignificant positive trend for precipitation may cause one to see precipitation not as a factor on streamflow decline, if not compared to the long-term precipitation record. As the historical record suggests there were increasingly more dry years after 1970 in the Yongding River Basin (Table 5). Only four indicators of upstream socioeconomic conditions were used to infer the relationship between human activities and streamflow decline, and no factors represented the industrial or urban sectors. Also the socioeconomic data was not annual and did not span the entirety of our streamflow dataset. Lastly, we did not estimate the impact of other key hydrological processes known to influence streamflow, such as evapotranspiration.

Despite the limitations, this analysis is an important first step to understanding the influence of recent precipitation variability on streamflow decline on a valuable river system to Beijing. Also it highlights a high research priority, which is clarifying the 
connection between upstream human activities, water use, and streamflow on the Yongding River to guide water resources management.

\section{Conclusion}

This research evaluates the impact of precipitation on streamflow decline on the Yongding River in Beijing from 1980 to 2010. Precipitation had an insignificant relationship with streamflow across the time-series at Guanting Reservoir, Yanchi, and Sanjiadian. The most probable abrupt change-points matched the start years of the recent climatic drought in Beijing, which were 1999 and 2000. However our results suggest the dramatic decline in streamflow was not from precipitation variability, but likely due to upstream human drivers. Precipitation changes in the postchange period (i.e., Beijing's recent drought) merely exacerbated already low flow conditions in the water scarce downstream reaches of the Yongding River.

In the 2000s, streamflow on the Yongding River in Beijing dramatically declined compared to the 1980s and 1990s. Downstream water allocations to the Yongding Corridor will come from different supplies which in part requires understanding how local conditions connect to rising upstream water use within a variable climate. We conclude the Guanting Reservoir is likely not a reliable primary water source for the Yongding Corridor due to continuous reductions in streamflow. Managers of the Yongding Corridor will need to better understand the influence of upstream water use on Guanting Reservoir outflow if regional water resources are used to maintain the newly constructed freshwater ecosystems.

\section{Acknowledgments}

This research was financially supported by Chinese Forestry Nonprofit Industry Scientific Research Special Project (No. 201204201), the National Basic Research Program of China (Nos. 2009CB421105, 2006CB403402), and the National Key Technology Research and Development Program of the Ministry of Science and Technology of the People's Republic of China (No. 2011BAJ07B05). We also thank the two anonymous reviewers for their useful suggestions.

\section{References}

Barnett, T.P., Pierce, D.W., Hidalgo, H.G., Bonfils, C., Santer, B.D., Das, T., Bala, G., Wood, A.W., Nozawa, T., Mirin, A.A., Cayan, D.R., Dettinger, M.D., 2008. Humaninduced changes in the hydrology of the Western United States. Science 319 (5866), 1080-1083.

Beijing Water Authority, 2009. Green Yongding River: the construction plan for an ecological corridor. Beijing, China (in Chinese).

Birsan, M.V., Molnar, P., Burlando, P., Pfaundler, M., 2005. Streamflow trends in Switzerland. J. Hydrol. 314 (1-4), 312-329.

Birsan, M.V., Zaharia, L., Chendes, V., Branescu, E., 2012. Recent trends in streamflow in Romania (1976-2005). Rom. Rep. Phys. 64 (1), 275-280.

Burn, D.H., Hag Elnur, M.A., 2002. Detection of hydrologic trends and variability. J. Hydrol. 255 (1-4), 107-122.

Chen, Z.S., Chen, Y.N., Li, B.F., 2013. Quantifying the effects of climate variability and human activities on runoff for Kaidu River Basin in arid region of northwest China. Theor. Appl. Climatol. 111 (3-4), 537-545.

Cheng, D., Chen, M., Shi, S.P., Ma, Z.Z., 2001. Impact of upstream human activities on the rainfall-runoff relationship in Yongding River. Des. Water Resour. Hydroelect. Eng. 20 (2), 19-21 (in Chinese).

Christensen, N., Lettenmaier, D.P., 2006. A multimodel ensemble approach to assessment of climate change impacts on the hydrology and water resources of the Colorado River basin. Hydrol. Earth Syst. Sci. 3, 3727-3770.

Dong, J., 2002. Sandstorms in Beijing-occurrence, Protection and Control. Master Thesis, Royal Institute of Technology, Stockholm.

Dooge, J.C.I., Bruen, M., Parmentier, B., 1999. A simple model for estimating the sensitivity of runoff to long-term changes in precipitation without a change in vegetation. Adv. Water Resour. 23 (2), 153-163.

Douglas, E.M., Vogel, R.M., Kroll, C.N., 2000. Trends in floods and low flows in the United States: impact of spatial correlation. J. Hydrol. 240 (1-2), 90-105.
Du, J., He, F., Zhang, Z., Shi, P.J., 2011. Precipitation change and human impacts on hydrologic variables in Zhengshui River Basin, China. Stoch. Environ. Res. Risk. Assess 25, 1013-1025.

Feng, Y., 2005. Cooperation management on competition uses of water resources shared by several Provinces - the case of Guanting Reservoir. Yunnan Geogr. Environ. Res. 17 (6), 9-14 (in Chinese).

Gao, Q.L., 2012. Analysis on the preliminary operational conditions of the circulating water pumping station located in Beijing Yongding River. Beijing Water 5, 46-48 (in Chinese).

Gao, P., Mu, X.M., Wang, F., Li, R., 2011. Changes in streamflow and sediment discharge and the response to human activities in the middle reaches of the Yellow River. Hydrol. Earth Syst. Sci. 15, 1-10.

Gautam, M.R., Acharya, K., Tuladhar, M.K., 2010. Upward trend of streamflow and precipitation in a small, non-snow-fed, mountainous watershed in Nepal. J. Hydrol. 387 (3-4), 304-311.

Gleick, P.H., 2003. Water use. Annu. Rev. Environ. Resour. 28, 275-314.

Guo, H., Hu, Q., Jiang, T., 2008. Annual and seasonal streamflow responses to climate and land-cover changes in the Poyang Lake basin, China. J. Hydrol. 355 (1-4) $106-122$.

Hamed, K.H., 2008. Trend detection in hydrologic data: the Mann-Kendall trend test under the scaling hypothesis. J. Hydrol. 349 (3-4), 350-363.

Jiang, S.H., Ren, L.L., Yong, B., Singh, V.P., Yang, X.L., Yuan, F., 2011. Quantifying the effects of climate variability and human activities on runoff from the Laohahe basin in northern China using three different methods. Hydrol. Process. 25 (16), 2492-2505.

Jones, R.N., Chiew, F.H.S., Boughton, W.C., Zhang, L., 2006. Estimating the sensitivity of mean annual runoff to climate change using selected hydrological models. Adv. Water Resour. 29 (10), 1419-1429.

Kendall, M.G., 1975. Rank Correlation Methods. Griffin, London.

Kundzewicz, Z.W., Robson, A., 2000. Detecting Trend and Other Changes in Hydrological Data. World Climate Program-Water, WMO/UNESCO, WCDMP45, WMO/TD 1013, Geneva.

Kundzewicz, Z.W., Robson, A.J., 2004. Change detection in hydrological records-a review of the methodology. Hydrol. Sci. J. 49 (1), 7-19.

Lettenmaier, D.P., Wood, E.F., Wallis, J.R., 1994. Hydro-climatological trends in the continental United States, 1948-88. J. Climate 7 (4), 586-607.

Li, H.Y., 2005. Impact analysis of historical forest change on Yongding River. China Water Resour. 18, 56-58 (in Chinese).

Li, L.J., Zhang, L., Wang, H., Wang, J., Yang, J.W., Jiang, D.J., Li, J.Y., Qin, D.Y., 2007 Assessing the impact of climate variability and human activities on streamflow from the Wuding River basin in China. Hydrol. Process. 21 (25) 3485-3491.

Liu, X., Zhao, G.Z., Deng, Y.Z., Chen, Y., Liu, J.G., Zhang, Z.M., Zhao, Y.F., Yang, Y., Wei, W., Liu, P.B., 2011. Evaluation model and application of ecosystem service value based on TM remote sensing in Yongding River. J. Hydroecol. 32 (5), 6-12 (in Chinese).

Lu, H.X., Gong, X.Y., Gu, B.J., Li, J.H., Zhu, X.F., 2012. Discussion of the water quality control measures by using the reclaimed water to recharge the landscape water body. Beijing Water 3, 41-43 (in Chinese).

Ma, H., Yang, D.W., Tan, S.K., Gao, B., Hu, Q.F., 2010. Impact of climate variability and human activity on streamflow decrease in the Miyun Reservoir catchment. J. Hydrol. 389 (3-4), 317-324.

Mann, H.B., 1945. Nonparametric tests against trend. Econometrica 13 (3), 245-249.

Mazvimavi, D., Wolski, P., 2006. Long-term variations of annual flows of the Okavango and Zambezi Rivers. Phys. Chem. Earth A/B/C 31 (15-16), 944 951.

Milly, P.C.D., Dunne, K.A., 2002. Macroscale water fluxes 2. Water and energy supply control of their interannual variability. Water Resour. Res. 38 (10), 1206. http:// dx.doi.org/10.1029/2001WR000760.

Pettitt, A.N., 1979. A non-parametric approach to the change-point problem. Appl Statist. 28 (2), 126-135.

Probe International Beijing Group, 2010. Beijing's water crisis: 1949-2008 Olympics (2010 update). Probe International, Canada. <http://probeinternational.org>.

Rosenberg, D.M., McCully, P., Pringle, C.M., 2000. Global-scale environmental effects of hydrological alterations: introduction. Bioscience 50 (9), 746-751.

Sen, P.K., 1968. Estimates of the regression coefficient based on Kendall's tau. J. Am. Stat. Assoc. 63, 1379-1389.

Smyth, R., Mishra, V., Qian, X.L., 2008. The environment and well-being in urban China. Ecol. Econ. 68 (1-2), 547-555.

Theil, H., 1950. A rank-invariant method of linear and polynomial regression analysis. I. Proc. K. Ned. Akad. Wet. 53, 386-392.

Von Storch, H., 1995. Misuses of statistical analysis in climate research. In: Von Storch, H., Navarra, A. (Eds.), Analysis of Climate Variability: Applications of Statistical Techniques. Springer-Verlag, New York, pp. 11-26.

Wang, H., Li, X.B., Long, H.L., Qiao, Y.W., Li, Y., 2011. Development and application of a simulation model for changes in land-use patterns under drought scenarios. Comput. Geosci. 37, 831-843.

Whitfield, P.H., Cannon, A.J., 2000. Recent variations in climate and hydrology in Canada. Can. Water Resour. J. 25 (1), 19-65.

Yang, Y.H., Tian, F., 2009. Abrupt change of runoff and its major driving factors in Haihe River Catchment, China. J. Hydrol. 374 (3-4), 373-383.

Yang, Z.F., Zhang, W.G., 2005. Upstream-downstream cooperation approach in Guanting Reservoir watershed. J. Environ. Sci. 17 (4), 676-680 (China).

Yu, M., Wei, Y.S., Liu, J.G., Liu, P.B., Zhang, Z.M., Wei, W., Wang, Y.W., Zhong, J., Yang, Y., Xiao, Q.C., Yu, D.W., Zheng, X., 2011. Impact of socioeconomic development 
on water resource and water environment of Yongding River in Beijing. Acta Sci. Circumst. 31 (9), 1817-1825 (in Chinese)

Yue, D.P., Liu, Y.B., Wang, J.P., Li, H.L., Cui, W.J., 2006. Physical principle of wind erosion on sandy land surface in southern Beijing. J. Geogr. Sci. 16 (4), 487-494.

Yue, S., Wang, C.Y., 2002. Applicability of prewhitening to eliminate the influence of serial correlation on the Mann-Kendall test. Water Resour. Res. 38 (6). http:// dx.doi.org/10.1029/2001WR000861.
Yue, S., Pilon, P., Phinney, B., Cavadias, G., 2002. The influence of autocorrelation on the ability to detect trend in hydrological series. Hydrol. Process. 16 (9), 1807-1829.

Yue, S., Pilon, P., Phinney, B., 2003. Canadian streamflow trend detection: impacts of serial and cross-correlation. Hydrol. Sci. J. 48 (1), 51-63.

Zhang C.Q, Zhang, B., Li, W.H. Liu, M.C. 2012. Response of streamflow to climate change and human activity in Xitiaoxi river basin in China. Hydro. Process. http://dx.doi.org/10.1002/hyp.9539. 